\title{
HBIM for the preservation of a historic infrastructure: the Carlo III bridge of the Carolino Aqueduct
}

\author{
Alessandro Conti ${ }^{1}$ (D) Lidia Fiorini $^{1} \cdot$ Rosanna Massaro $^{1} \cdot$ Camilla Santoni $^{1} \cdot$ Grazia Tucci $^{1}$
}

Received: 10 April 2020 / Accepted: 12 August 2020/Published online: 20 August 2020

(C) The Author(s) 2020

\begin{abstract}
The research on Carlo III bridge in Moiano (Benevento, Italy) has been an opportunity for testing the HBIM methodology to the architectural heritage in terms of not only gathering information but as a design tool. The bridge, almost without previous drawings and documents, was surveyed with an integrated approach using laser scanner, photogrammetry and topography. Data produced a metrically reliable HBIM model, complete with graphical and non-graphical information, to be used in a maintenance and restoration project.
\end{abstract}

Keywords HBIM · Infrastructures · Cultural heritage · Carolino Aqueduct · Integrated survey

\section{Introduction}

In a context of challenging issues for cultural heritage such as environmental and natural hazards, climate change, negative anthropogenic actions or simply lack of awareness, it is necessary to optimize resources in a sustainable way. It is well known that knowledge and documentation are the prerequisite for an effective conservation of cultural heritage and that this sector has always been the meeting point of multidisciplinary knowledge and expertise. Nevertheless, the traditional methods of collecting, managing and sharing information followed different paths in the humanistic, technical and scientific fields and their specializations. Digital technologies are innovating all these areas. Digital humanities, informative models, digital twins and XR technologies offer different but correlated answers to create a Common Data Environment in which decision makers can address resources and interventions in the most effective way.

The new information management systems also make it possible to disseminate knowledge of hitherto less well known and poorly documented works. The possibility to manage and process a full collection of data in a single container has opened the way to the application of the BIM methodology

Alessandro Conti

alessandro.conti@unifi.it

1 DICEA - Department of Civil and Environmental Engineering, University of Florence, Via di S. Marta 3, 50139 Florence, Italy to existing buildings and cultural heritage known as Heritage Building Modelling - HBIM) (Murphy et al. 2009).

Three-dimensional queryable and implementable models become "smart repositories" of all data related with the building, as well as tools to support the elaboration of restoration and planned maintenance projects. The viewpoint is that of a 4D model (Xiao et al. 2018), which embraces the past, present and future to understand the damages occurred in the past, the current conditions and to plan monitoring and interventions.

The use of BIM tools in the field of architectural heritage involves some forcing, since they were designed for new construction and not for the irregularity of the historic ones, but today they can represent the most effective of the management systems being experimented so far.

The aim of the paper is to show the application of the HBIM method to a case study never documented before (even with traditional techniques), i.e. the Carlo III bridge in Moiano. The peculiarities of the study consist in (i) the fact that the artefact is part of a very complex historic aqueduct (the aqueduct of the Royal Palace of Caserta), so this method could be applied to the whole building or other ancient infrastructure works, and (ii) a possible workflow for mapping the surface degradation and restoration works in HBIM models.

\section{State of the art}

BIM-Building Information Modelling - is the digital representation of a structure in the form of a parametric model 
containing all the information about a building throughout its life-cycle, from the project, to its construction, management and demolition. It is an informative, interdisciplinary, shared and constantly evolving model that can potentially connect data on geometry, materials, structure, thermal properties and energy performance, plants, costs, safety, maintenance, demolition and decommissioning.

This methodology, born mainly for collaborative design, is becoming increasingly effective for the management of assets. As a result, there is an interest in extending its application to existing buildings too. For this reason, the BIM approach has also found fertile ground in the infrastructure sector (InfraBIM) (Tucci et al. 2019b) and in particular in the field of bridges, both for new and existing constructions. BIM simplifies the inspections and assessment of structures and helps decision makers in managing more efficiently the inventories and in automating operational practice, with significant savings in maintenance and scheduling costs.

In Italy, the Ministry of Infrastructure and Transport decreed the mandatory use of modelling methods and tools in public works (D. Lgs. 560/2017) in order to promote the raising of efficiency and organization levels through digital management of project information content. The attention paid to this sector is clearly referable to new constructions but, above all, to large-scale infrastructures, in particular bridges and viaducts, built during the last century and designed for an expected life span of 50 years.

The same advantages motivate the growing interest in applying the BIM methodology to various aspects of Cultural Heritage management, both for restoration and museum management (Tucci et al. 2019a), or for communication projects also with XR tools (Brioso et al. 2019; Pybus et al. 2019).

The objective is to pursue an adequate knowledge of the artefact that is to be preserved, progressively replacing the traditional methods of the restoration and structural reinforcement projects with new tools for managing both existing information and new interventions. Thus, the transition from BIM to HBIM (Historic Building Information Modelling) took place. HBIM, starting from survey information (Bolognesi 2018) through the import of point clouds into the management system, allows a parametric digital representation of an existing building or structure.

As far as bridges are concerned, many of them are close to the end of the project life and need actions to assess their safety. Previtali et al. (2019) explain the implementation in a BIM model of load testing data in the form of numerical results and graphs like displacements measured during the monitoring phase, GPR (Ground Penetrating Radar) data to inspect internal structures, crack maps, stratigraphy, mechanical characterization, etc. for providing a single access point for professionals involved in developing the maintenance programs.

León-Robles et al. (2019) describe the creation of a BIM model for a historic bridge. Authors built the initial state from the original blueprints, then found the deformation of the structural elements comparing it with a laser scanner survey.

Another method of representation of the information collected during the inspection is that of "Damage Cubes," parametric parallelepipeds used to represent the volume and severity of a certain damage in a particular position of the bridge; they allow operators to achieve a high degree of visual detail in identifying problem areas (McGuire et al. 2016).

The use of BIM software for damage documentation would facilitate the inclusion of such information in any other analysis tool, although an improvement in the interaction between different systems is still needed to partially or completely automate the process.

In the context of heritage bridges with an architectural value it is necessary to deal with the conservation aspects, i.e. the alterations suffered by the materials over time, negligible in new constructions, in order to preserve the integrity and the original aspect of the building and respect its historic and artistic value. In the traditional operative practice of restoration, interventions were usually described on 2D drawings containing additional documentation. Interventions (like cleaning of degraded surfaces, removals and protective treatments) were represented as areas with different colours or hatchings on $2 \mathrm{D}$ elevations, plans and significant sections. The quantification of the areas affected by different decays and their visualization has the limits of 2D drawings (Negri and Russo 2008; UNI 11182:2006).

Even independently of the use of the BIM methodology, various methods have been developed for the digital management of decay information.

Given the importance of the characterization of the decay mechanisms for conservation processes, several surveying and monitoring systems have been developed. In small and enclosed spaces, $360^{\circ}$ imagery was processed for a fast mapping and monitoring of decay, obtaining metric data from panoramic raster images (Barazzetti et al. 2020).

For the archaeological site of Pompeii (Campanaro et al. 2016), a three-dimensional monitoring system has been developed combining of 3D visualization and GIS. It provides specialists with a guideline to manage the decay processes of the "at risk" heritage, subdividing the 3D mesh model into approximately plane sub-elements and depicting the decay on the obtained 2D maps.

In other cases, as for the restoration of the Neptune Fountain in Bologna (Apollonio et al. 2017), the survey allowed the construction of a 3D surface model on which thematic mapping was carried out. A digital archive of all monument related data, starting from the previous restoration actions to those in progress, was carried out through an on-line application. It is possible to navigate freely on the 3D model of the art-work, to have access to the documentation (texts, scientific analysis reports, images, graphs) and to the portions of the sculpture to which it refers (location of the documentation). It is also possible to draw the 
data related to the conservation directly on the surface model (through interactive insertion of points, polylines or regions and the associated metadata), obtaining a 3D geo-referenced visualization, usable in the diagnostic phase or for future inspections and maintenance operations.

In these cases, models do not rely on such a structured database as BIM and, above all, they only describe the surface of the artefacts, neglecting their internal structure.

A multi-disciplinary diagnostic approach, and the integration of GIS and HBIM, instead, supported the creation of a database including qualitative and quantitative data and complete conservation project with an integrated use of GIS and BIM tools (Tsilimantou et al. 2020).

Other studies tested in recent year artificial intelligence for the automatic recognition of decay on building materials and their mapping also on BIM objects. Borin and Cavazzini (2019) created a BIM of a reinforced concrete bridge using a photogrammetric survey and applied a neural network to imagery for detecting spalling. Masked images were backprojected on the BIM model to indicate the affected areas. An automatic process has been developed for the detection of cracks on concrete bridges, starting with the generation of flight paths for an unmanned aerial vehicle (UAV) photogrammetric survey, to the 3D modelling (not in BIM environment) and identification of typical damage patterns through Machine Learning (Morgenthal et al. 2019). Artificial intelligence would significantly reduce the time-consuming classification of pathologies, but the process is still to be consolidated, mostly where multiple decay patterns are present.

For building documentation, surface models accurately describe the smallest details of a geometry but require a complex processing (Tucci et al. 2014). Therefore, the advantage of using the HBIM methodology lies in the optimization of processing time, maintaining a sufficient accuracy in relation to the goals.

\section{Carlo III bridge}

Located in Moiano (Benevento, Italy), a small town in Southern Italy, Carlo III bridge over the river Isclero is an infrastructure of the Carolino Aqueduct (Canestrini and Iacono 2007), the water supply system of the Royal Palace of Caserta. The project of the Royal Palace and the Aqueduct was commissioned by Carlo III di Borbone, King of Naples and Sicily, to the architect Luigi Vanvitelli, in the second half of the eighteenth century (Fig. 1).

The Carolino Aqueduct is underground for $37 \mathrm{~km}$ and emerges in some sections only, that are the "della Valle" bridge (in the Maddaloni Valley), the Tagliola Bridge (at Durazzano) and the Carlo III bridge, which is the closest to the Fizzo springs, where the water that feeds the Royal Park and Palace is collected (Fig. 2).
The Carolino aqueduct and therefore also the Carlo III bridge are certainly infrastructures, but their design, which combines technology and forms typical of classical culture, are a clear manifestation of a far-sighted government that expressed its power by marking and designing the territory (Fig. 3).

The bridge was built in order to cross the aqueduct over the river Isclero and without any connection with the local road network. It is about $150 \mathrm{~m}$ long above ground and almost $7 \mathrm{~m}$ high. The structure is entirely made of local yellow tuff, which is certainly extracted in the nearby quarries, while the perimeter ashlars, the plaques, some elements of the curb and the pavement are made of limestone, also local, characterized by a lighter, almost white colour (Fig. 4).

Carlo III bridge is made up of four round arches separated by buttresses and two "shoulders" connecting and gradually entering into the ground, following the natural slope. Horizontally, it can be considered divided into a lower level (which includes the arches), an intermediate level, externally delimited by two limestone string courses (strongly degraded but still clearly recognizable), and an upper level, walkable but without parapets (Fig. 5).

The internal duct is across the second and third levels. It is made of tuff and waterproofed by hydraulic mortar. The internal section of the water duct is about $1.20 \mathrm{~m}$ wide and $1.80 \mathrm{~m}$ high at the top and is covered by a barrel vault. The conduit is still working today: through it, in fact, the water collected from the sources of the Fizzo reaches the fountains of the Royal Palace of Caserta, despite the precarious state of conservation of the entire aqueduct and in particular of this bridge.

The lack of maintenance, aggravated by uncontrolled interventions over the decades, has led the bridge to a state of great vulnerability compared with its initial condition. To mention just a few, the removal of tuff and limestone ashlars attempts at unauthorized water supply (with the insertion of concrete and metal pipes in the duct, the growth of thick vegetation close to and on the bridge, which roots penetrate in the masonry). Currently, the building is showing evident damages and quite alarming cracks. Moreover, there is an overall decay of stone materials due to the exposure to atmospheric agents and pollution and characterized by typical pathologies (patina, efflorescence, alveolization, disintegration, etc.) on the external surface (Gennaro and Fuscaldo 1991).

The importance of this infrastructure, not only in itself but especially within the Carolino Aqueduct, included in the World Heritage List (UNESCO 1997), underlines the need of a complete documentation and a maintenance plan, until now absent, to implement more effective management and maintenance processes, shared and potentially applicable to the whole aqueduct. 


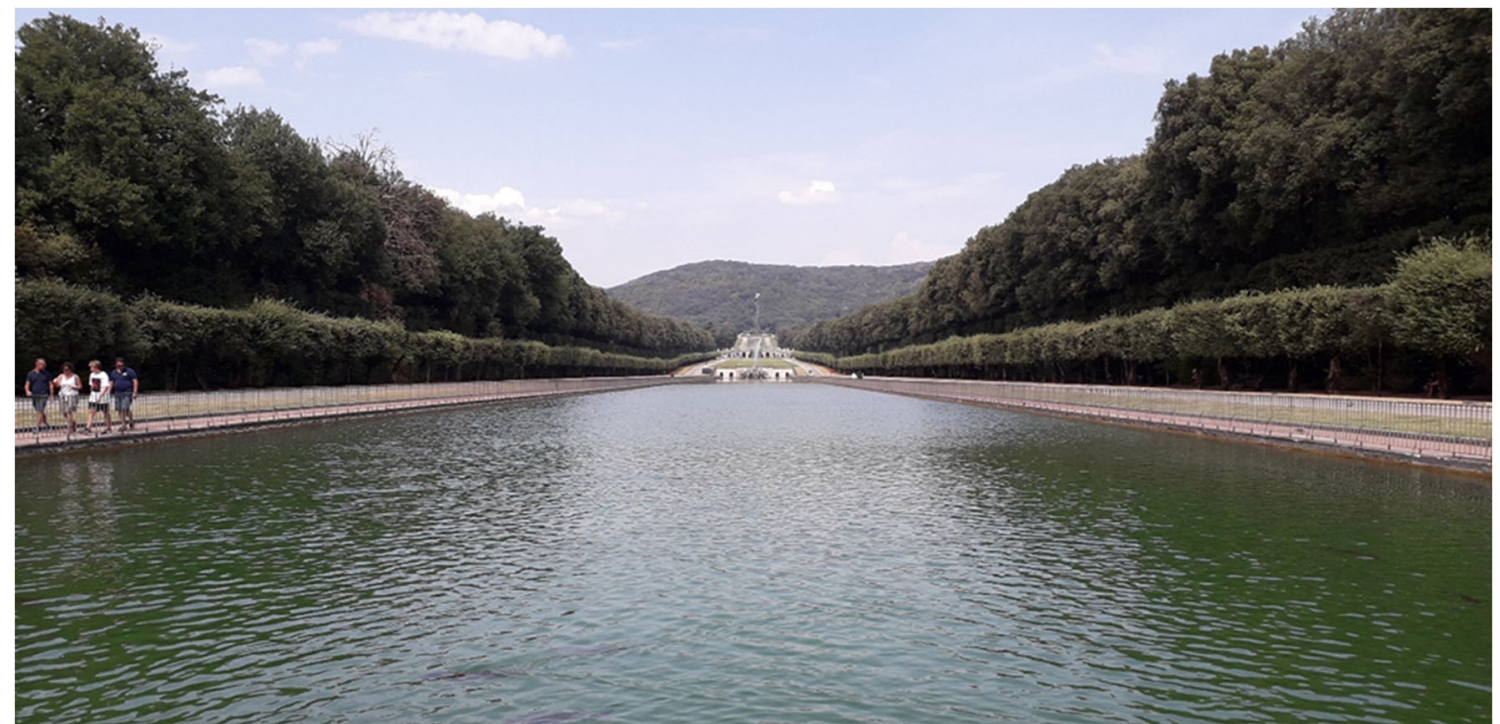

Fig. 1 The fountains and the park of the Royal Palace of Caserta, fed by the Carolino Aqueduct

\section{Integrated survey}

Geometric data acquisition was carried out in two-and-a-half days according to the principles of integrated survey, with laser scanning and both terrestrial and UAV photogrammetry referred to ground control points measured with total station and GNSS (Tucci et al. 2017).

The site morphology constrained the survey operations. The bridge itself constitutes a barrier that precludes the mutual visibility between adjacent areas. The dense vegetation (both spontaneous and cultivated) and the river Isclero (even if small) caused occlusions, constrained the position of the topographic vertices and scanner stations and also hindered the acquisition of photogrammetric imagery. In addition, the steep concrete banks prevent a free access to the river.

The geometry of the building was acquired with a phaseshift laser scanner, performing 47 scans on the bridge and adjacent terrain with an angular step of $6 \mathrm{~mm}$ at $10 \mathrm{~m}$ and a final resolution on the object of about $3 \mathrm{~mm}$.

A photogrammetric UAV survey was carried out to obtain a general map of the bridge and the surrounding area. Considering the maximum height of the trees in the area, images were taken at an altitude of about $30 \mathrm{~m}$ with a GSD of about $9 \mathrm{~mm}$. Further UAV images of the top and walls of the bridge were acquired at close range with a manual flight to obtain high-resolution orthophotos of the walls and top of the bridge, useful for the detection of the materials and decay. Other images were taken from the ground with a reflex camera for integrating the laser scanner data and surveying with photogrammetry all the details of the construction. Due to the mentioned obstacles, it was not possible to set a closed traverse with total station so it has been measured a baseline with four spurs. Network vertices were also measured with GNSS for geo-referencing. From the network vertices, 12 targets on the ground and 84 targets on the bridge walls were acquired. The target coordinates were used both for the scan alignment and for scaling and referencing the photogrammetric surveys by UAV and from the ground, so all data are in the same reference system to integrate each other. An effective automatic processing is possible if original data include a sufficient quantity of stable features, which can be distinguished in:

- geometric features for laser scanning,

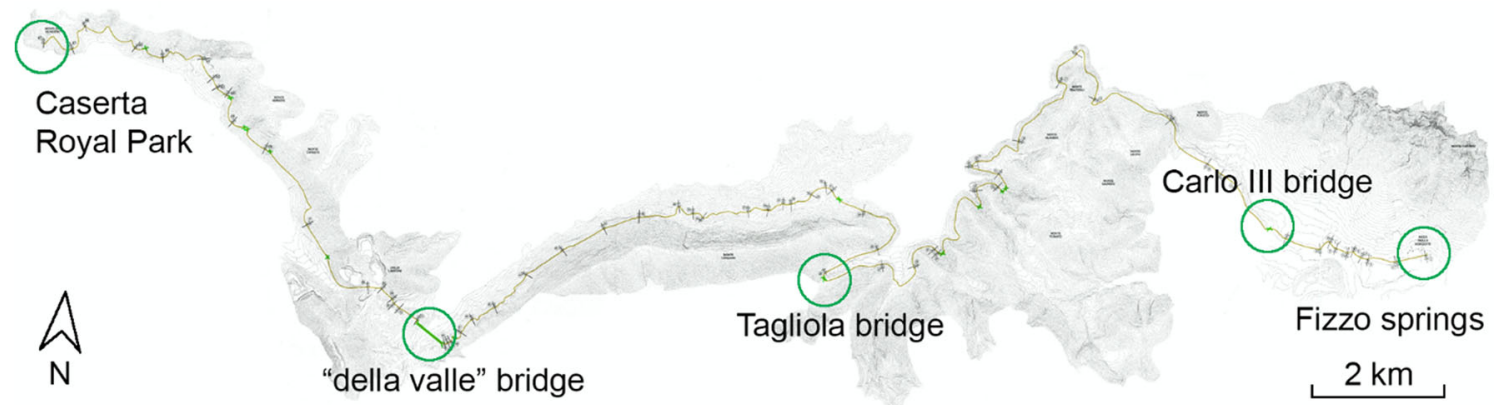

Fig. 2 The route of the Carolino aqueduct from the Fizzo springs to the Royal Park of Caserta, with the indication of the three monumental bridges 
Fig. 3 Carlo III bridge, Moiano $(\mathrm{BN})$, aerial image showing the crossing of the Isclero river

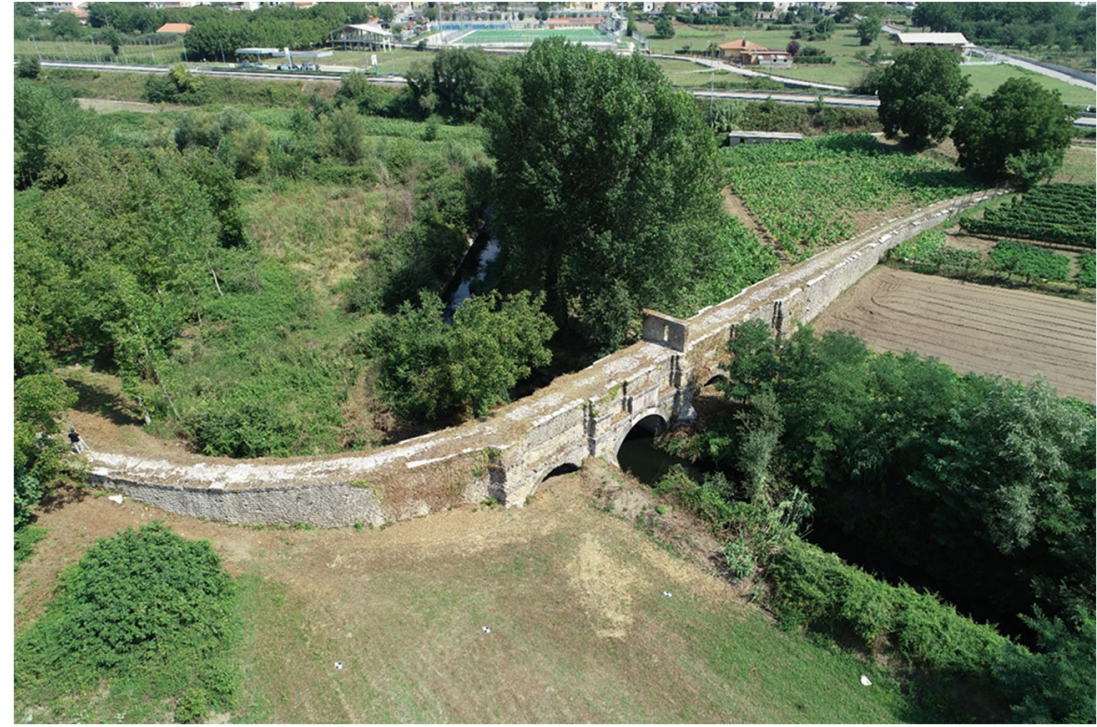

- the digital visualization of the object (geometry, materials, state of decay, etc.);

In this case, this was not always possible, because the bridge and the surrounding terrain were covered by a dense vegetation moved by the wind. Again, in a few cases the predominantly linear shape of the building caused some accidental sliding between relatively featureless regions. For these reasons, a manual processing was required. Dataset was subdivided into consistent portions which were automatically processed and then merged by using the coordinates of the targets measured by the vertices of the topographic reference network.

After registration, the mean distance between the point clouds obtained by laser scanning and photogrammetry resulted $3 \mathrm{~mm}$, being the outliers referred to the parts covered by vegetation (Fig. 6).

\section{BIM modelling and thematic maps}

As stated, BIM can be a significant turning point for the overall maintenance and management of historic infrastructure as well. The adopted approach aims to

Fig. 4 The main materials of the Bridge: a the local limestone with the presence of a disintegration phenomenon and a superficial patina; $\mathbf{b}$ the yellow tuff, and the clear lesion on the South elevation
After importing the decimated point cloud on the chosen authoring software (Autodesk Revit), a segmentation of the point model is needed, in order to identify homogeneous elements with the same information content. The used BIM software has groups of parametric elements, called "families" (e.g. walls, floors and pipes), designed for the modelling of new buildings (Wing 2017) and, consequently, often unsuitable for modelling heritage buildings and even more unfit for historic infrastructures.

The currently available standard components cannot accurately model the irregularities of the building, which is essential in preservation (Boeykens et al. 2018). This is still a major limitation in the use of BIM authoring software in the architectural and archaeological heritage
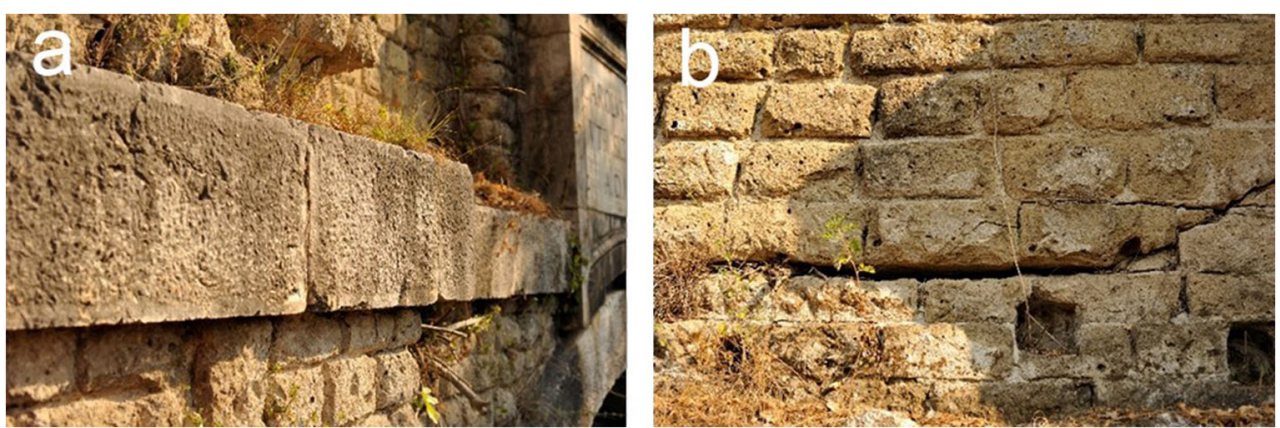


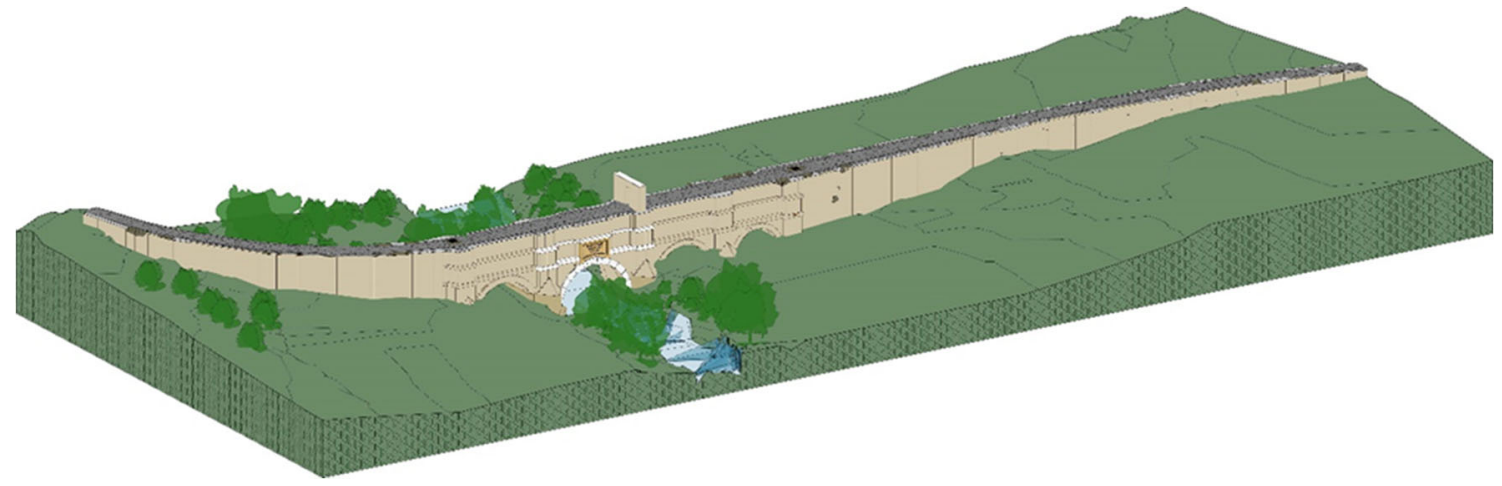

Fig. 5 Carlo III bridge, the HBIM modelling of the geometry, the surrounding terrain and the watercourse

fields, and many tweaks have been proposed to address this issue (Banfi 2020).

Due to the irregularity of the surveyed object, it was necessary to use so-called "in-place models" to represent the existing geometry as closely as possible, but without all the parametric properties of a standard family (Fig. 7).

The interior of the bridge was also represented in the same way with "void forms" tools, obtaining a reliable reconstruction of the geometry and the internal functioning of the bridge.

The environmental context was modelled too, even if in a simplified way, inserting the ground in the surrounding area, the masses of the trees and the watercourse. The context of the bridge is in fact relevant from several points of view. On a local scale, the current structural instability could be related with the condition of the riverbed and the terrain. On a landscape scale it is clear that such a relevant structure was designed not only to cross a small river and a shallow valley, but as a landmark, so it is important to consider it in its scenery.
HBIM modelling also must face another issue which is not present in new constructions. Often the inner texture of a building is not completely known, so there is the risk to build a dumb model. Trying to overcome this issue, every kind of information was linked to Carlo III bridge basic components. Technical data include materials, their characteristics and processing techniques. The main materials used for building the bridge, which are Neapolitan yellow tuff and limestone, have been added to the materials library. They are linked to a brief description, an indication of the presumed origin and to informative websites. Other information includes all historic data useful to reconstruct phases and interventions, like archival or printed sources, images and also oral history, with testimonies of local people on the works occurred in last decades. Finally, in absence of other data, also the working hypotheses aroused during the research were included. As example, it was possible to inspect only a limited portion of the interior of the conduit through a manhole above the bridge in the straight

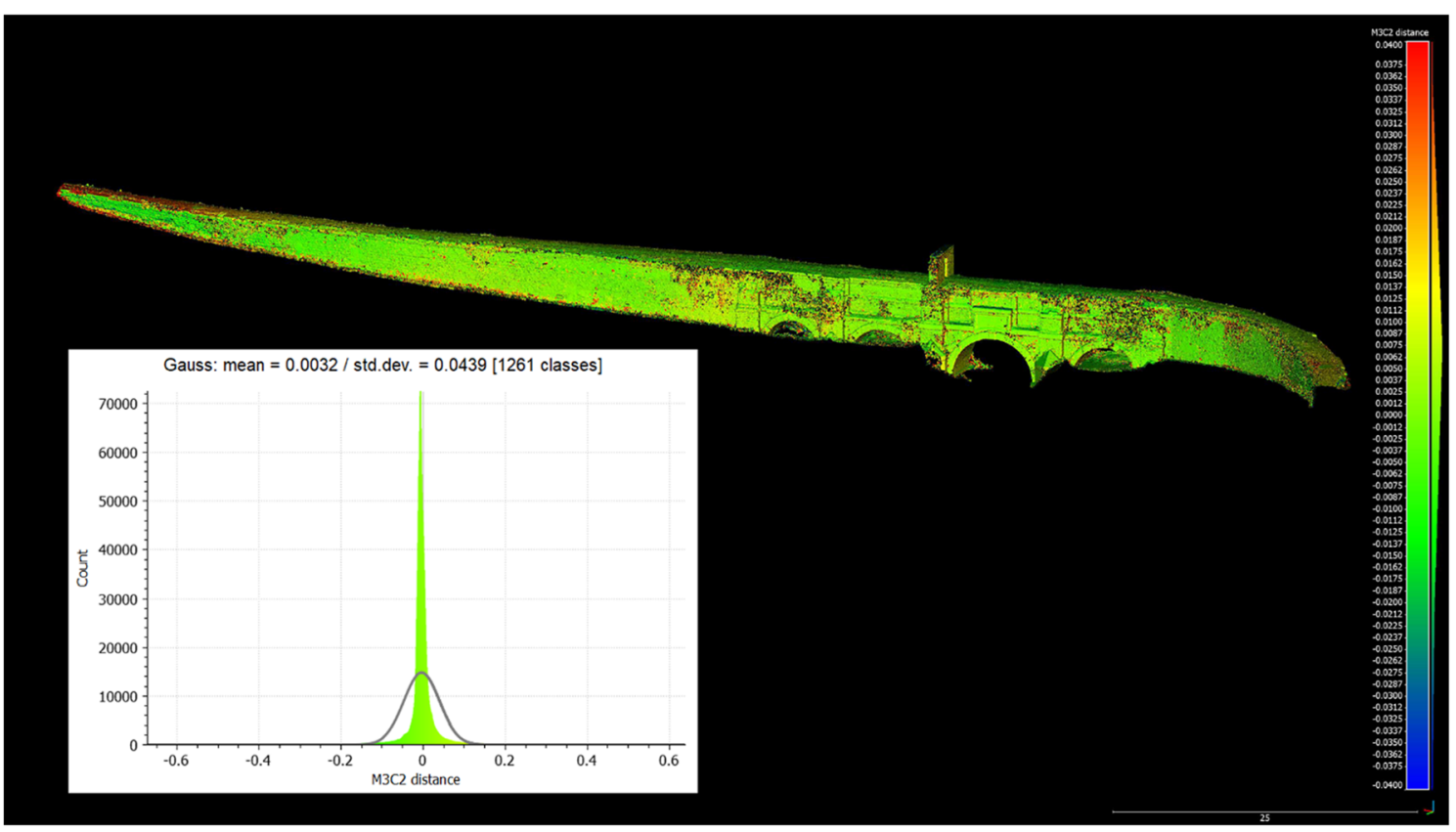

Fig. 6 Comparison between point clouds acquired by laser scanning and photogrammetry 

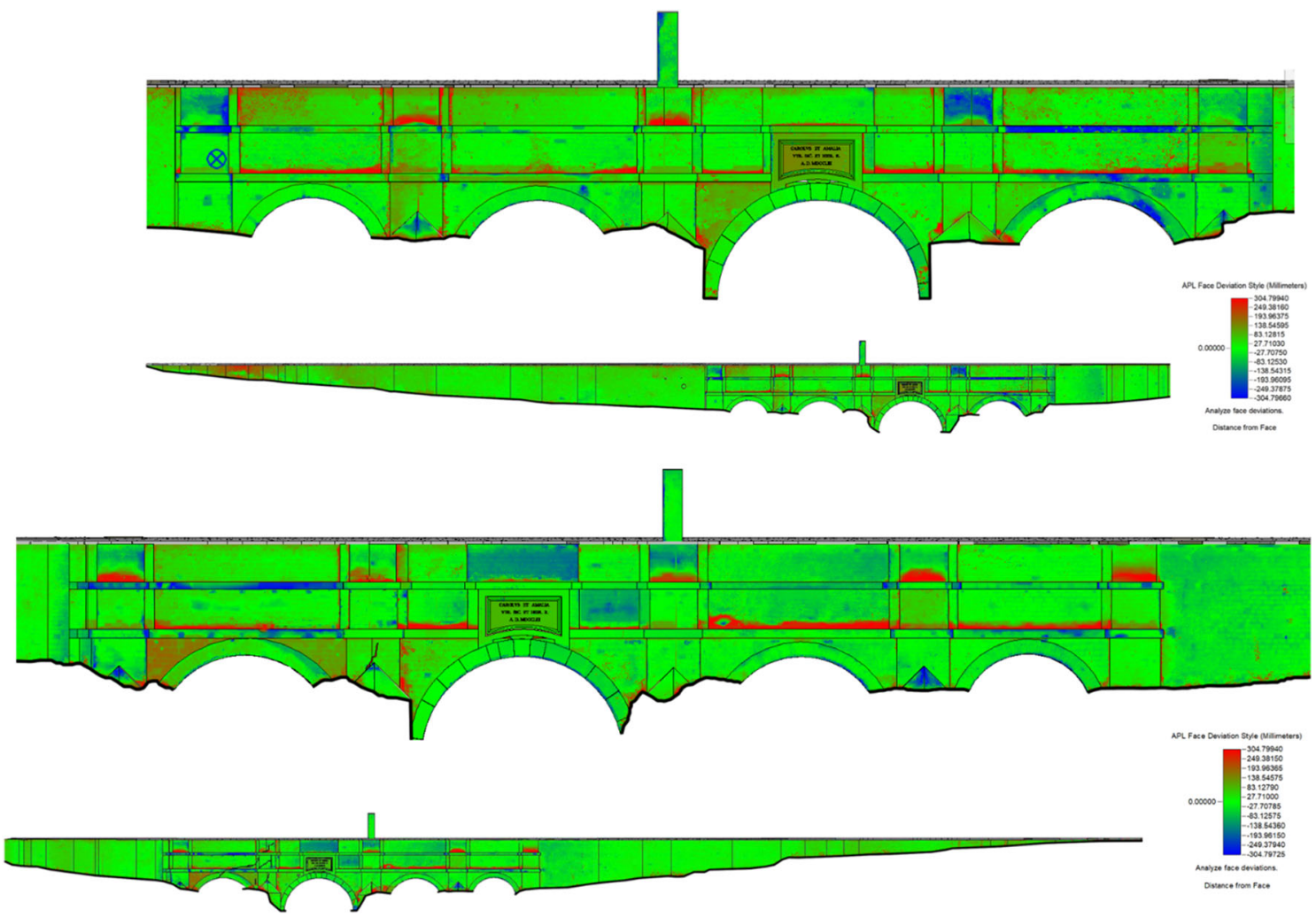

Fig. 7 Point cloud and BIM model deviation map. The diffused modelling error is about $2.7 \mathrm{~cm}$, mainly related to masonry ashlars. Red areas are related to infesting vegetation (not included in the 3D model); blue areas to very irregular portions or missing parts

portion of the eastern side (Fig. 8). Data about dimensioning, materials and pipes have been, temporarily, extended to the entire bridge.

An advantage of BIM exactly lies in the opportunity to add and modify data, if in the future other investigations will give new data and push to rethink the current interpretation.

By selecting an object, it is possible to retrieve all information, including photos, by means of the attributes of the material.
Another important aspect is the attribution of a Level of Reliability to each object. Actually, some of them are modelled according to several hypotheses, like the already mentioned inner duct or the load-bearing structures and foundations. For this reason, it is important to distinguish the surveyed elements from the hypothesised ones, for example with different colours (Aparicio Resco and Figueiredo 2017).
Fig. 8 The inner duct, modelled according to the currently available data

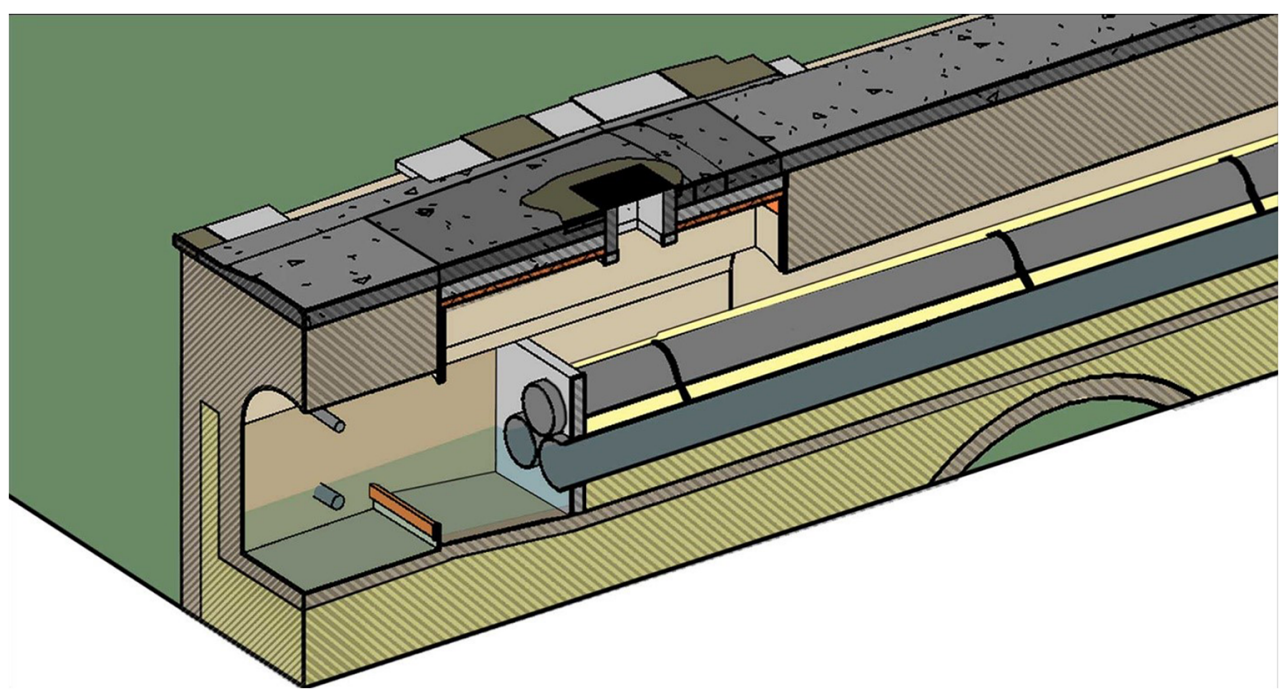




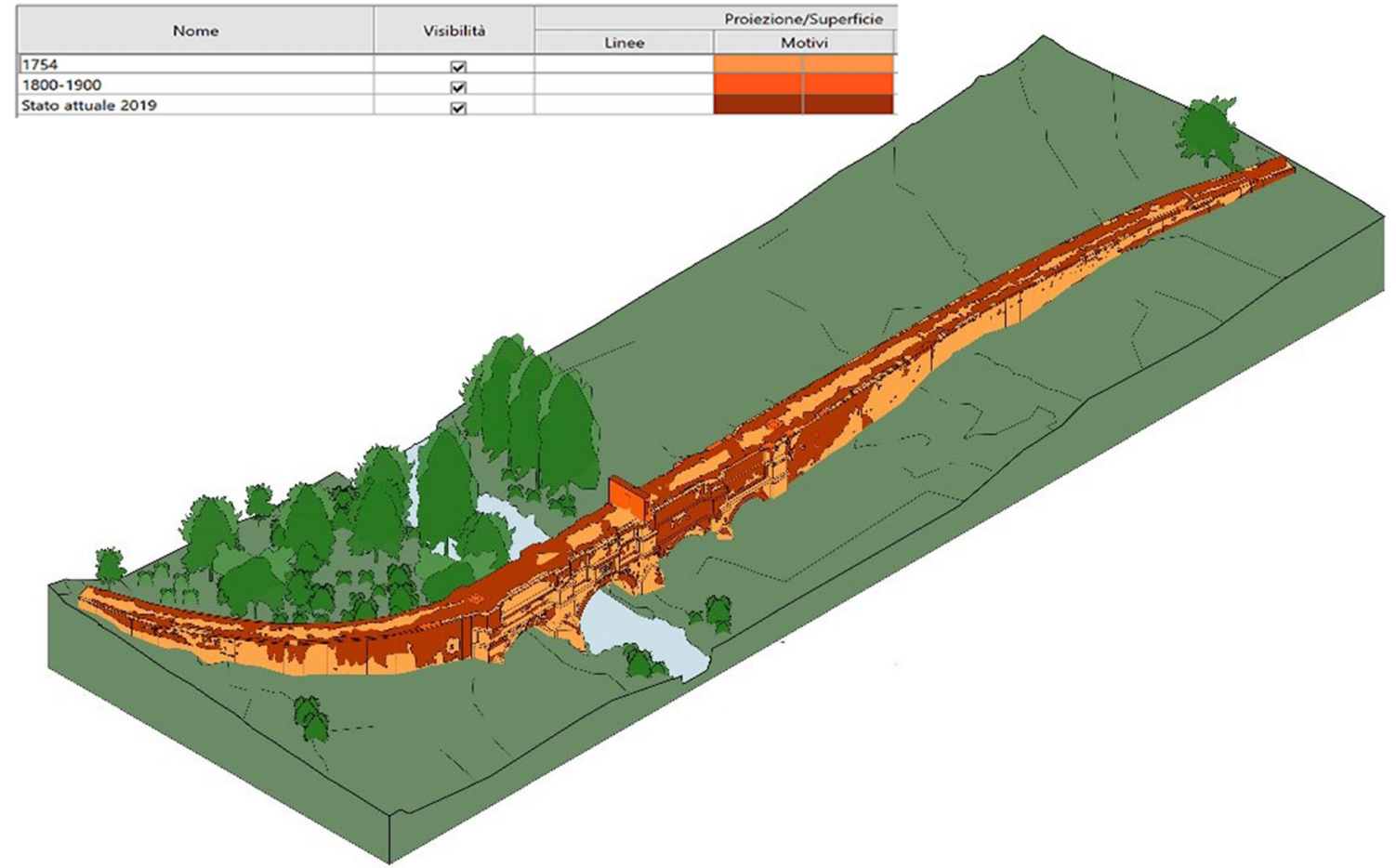

Fig. 9 Time sequence of the bridge, obtained filtering the construction phases in the HBIM model

Other information concerns the date of the interventions. All phases after the construction (about 1754) were identified and attributed to bridge elements. Cross-correlating the above-mentioned data, it is possible to create thematic maps, for showing, as example, the construction phases of the parts of the building (Fig. 9).

\section{Decay mapping}

Even including all collected data on materials and history, the HBIM model is not sufficient for the preservation project. On the most recent phase, corresponding to current survey, all the deterioration phenomena and crack patterns were accurately mapped. This was obtained by importing the orthophotos into

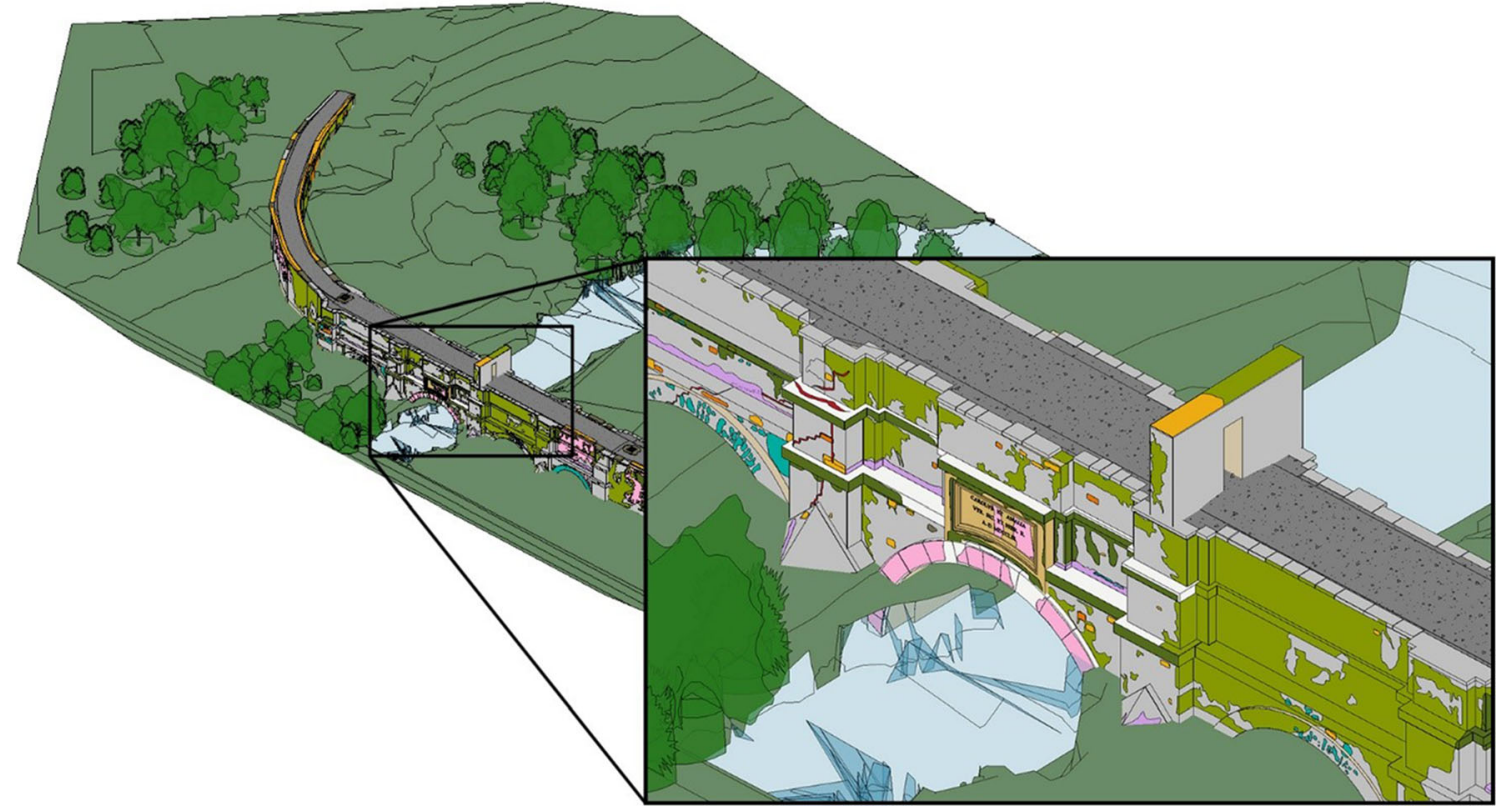

Fig. 10 Representation of decay using "in-place" models 


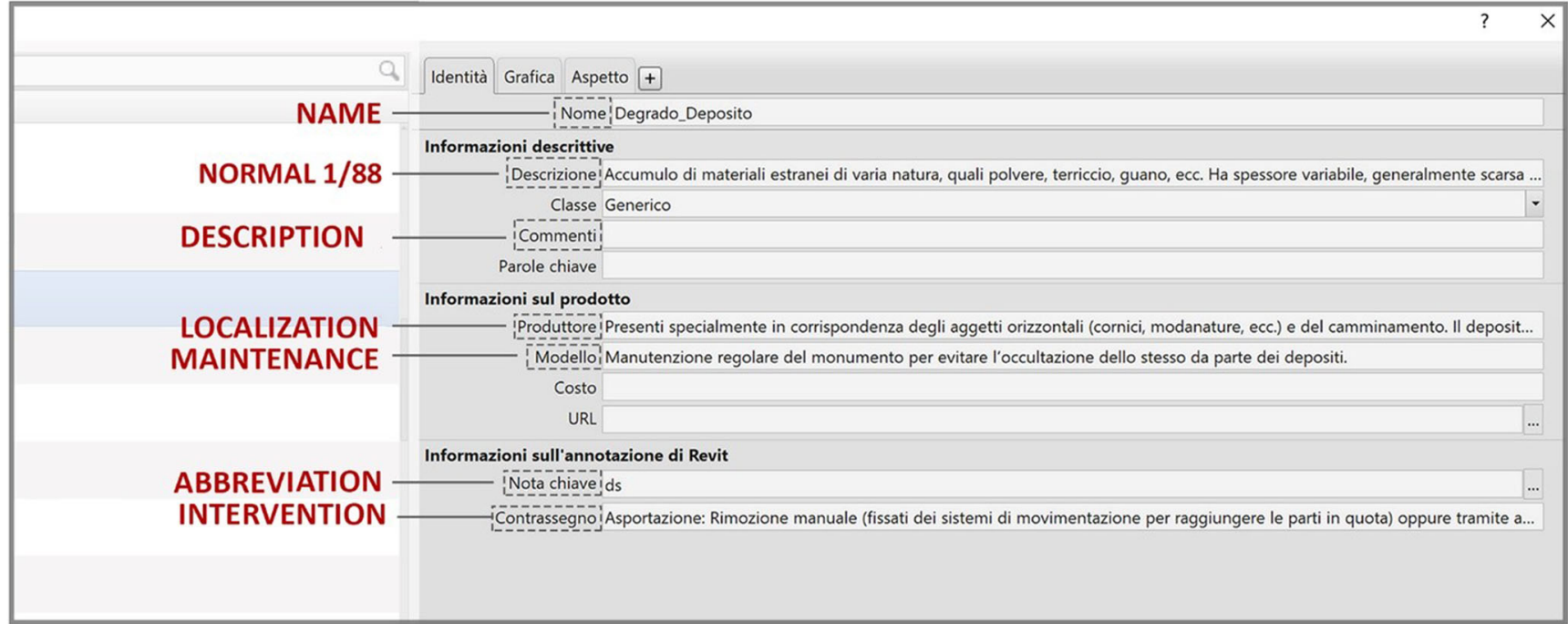

Fig. 11 Information on the decay and interventions inserted reassigning the parameters of materials in the parameters browser

BIM software and vectorizing the different pathologies on the flat surfaces of the model (included the parallel ones to the horizontal plane). The selected areas were modelled as millimetre-thick surfaces and classified by degradation pattern. This manual process is undoubtedly accurate but is very time-consuming (Fig. 10).

All kind of information can be associated to the surfaces representing the decay: description of the pathology (according to the Italian norm UNI 11182:2006), photographic images, textual descriptions and 2D dimensioned drawings (from manual survey) to state the depth of the cracks (Fig. 11).
In BIM, "Schedules" tool allows the data extraction. A schedule of decay patterns (Fig. 12) has been created, including the information related to the description and quantity of every kind of deterioration. When the geometry is modified, schedules are automatically updated, allowing the monitoring of the evolution of deterioration.

Once the characterization of materials, the localisation of every kind of deterioration and its quantity, is known, the conservation and structural reinforcement plan can be represented and computed on the model (Fig. 13). As described about decay representation, interventions can be attributed to

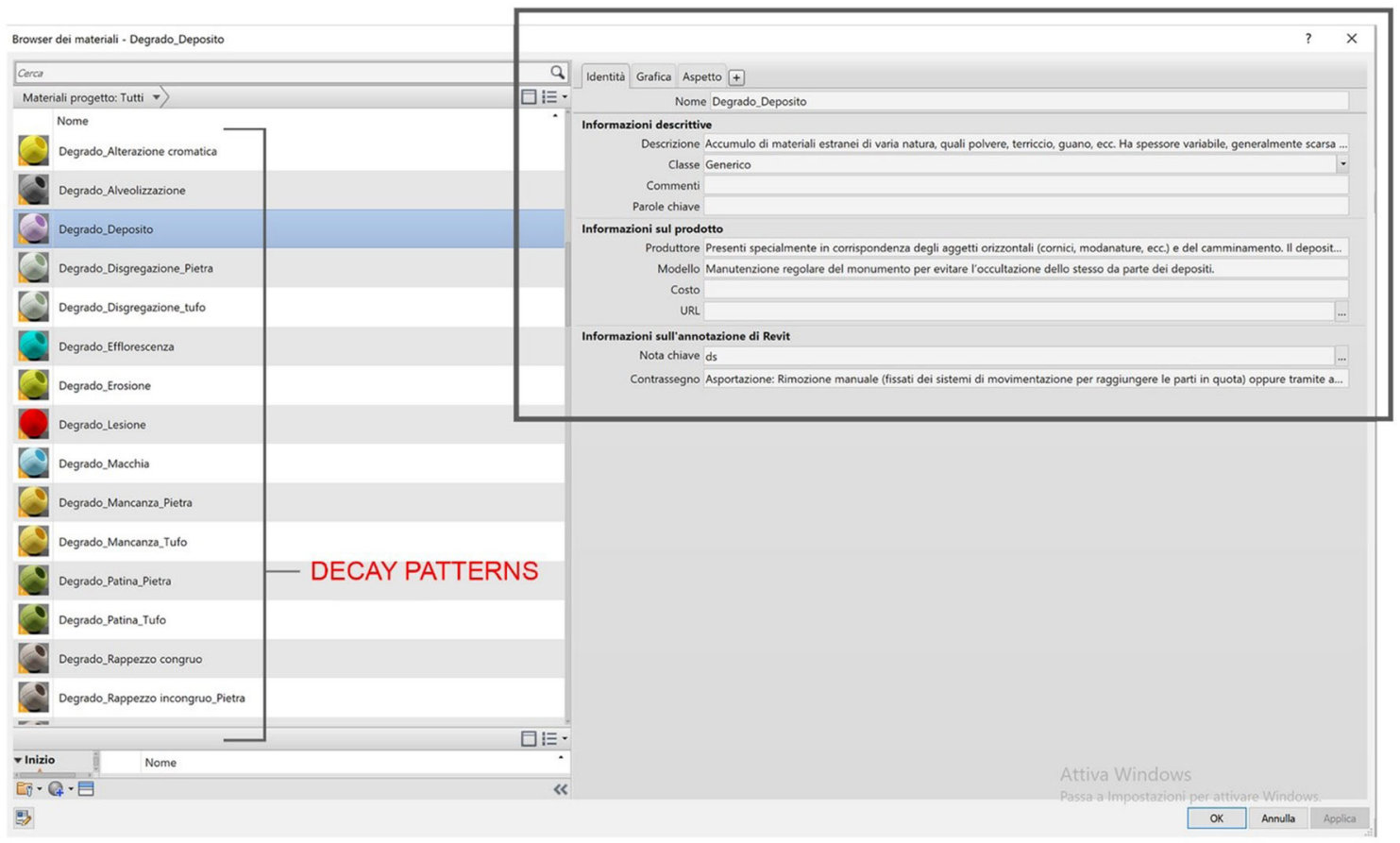

Fig. 12 A schedule with a summary of the decay patterns 
Fig. 13 Representation of interventions on the HBIM model

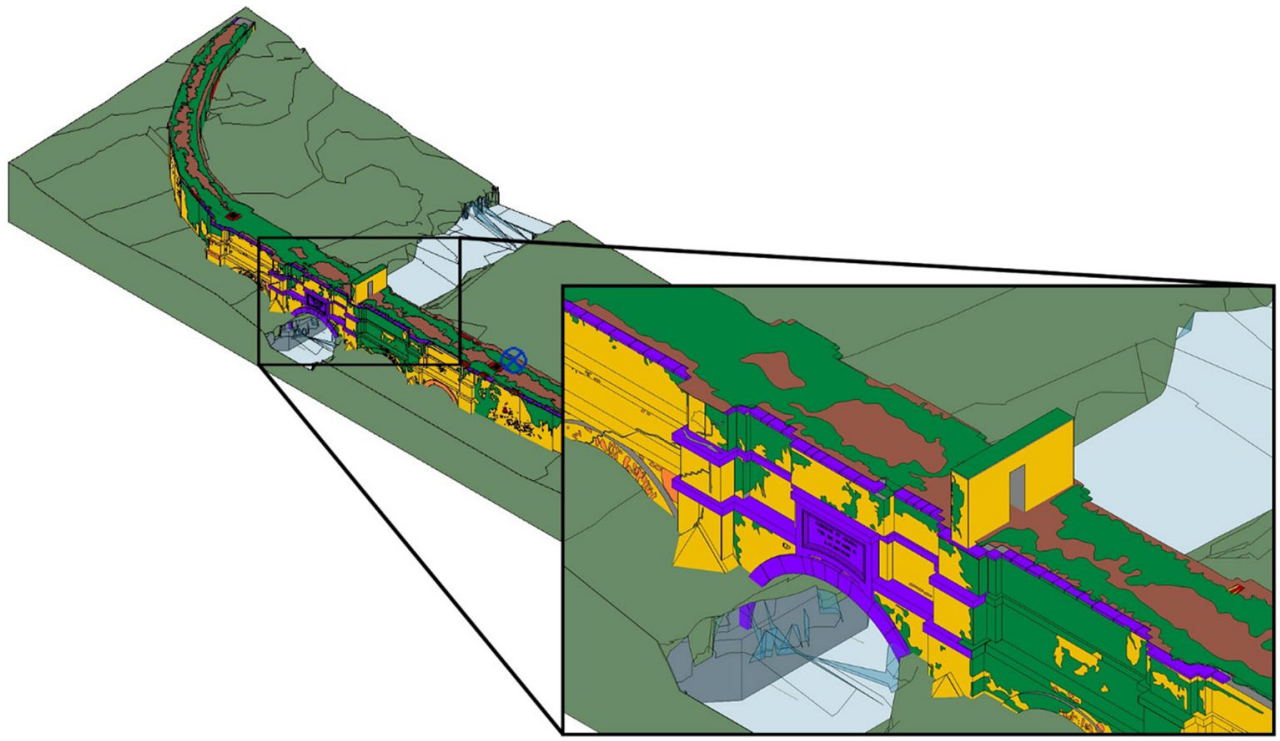

single objects or portions of surfaces, indicating the corresponding surface of the model and associating all the necessary information, e.g. name, steps, images, technical data sheets and tutorials. As for decay, it is possible to create schedules containing the quantity of the surfaces on which every intervention is required, together with detailed procedural descriptions, products to be used and other working solutions. As in the traditional restoration practice and in building sites printed drawings are still very common; it is also possible to export the $2 \mathrm{D}$ views in usual CAD formats or other data included in schedules for producing proper bills of quantities.

\section{Conclusions}

The paper shows an application of HBIM on a eighteenth century infrastructure, which was lacking of any reliable documentation until now. The potential of HBIM methodology has been exploited by modelling the current phase using data coming from an integrated 3D survey.

The advantage of BIM technology lies in the possibility to digitally manage all the information of a building and in the described case study this potential has been exploited in several ways:

- from the geometric and spatial data management side, using data coming from an integrated 3D survey to accurately model the bridge;

- from the point of view of information content, associating the elements with semantic content related to materials, degradation and conservation interventions.

Therefore, the previous phases have been reconstructed obtaining a 4D survey. The HBIM model guarantees the conservation of the information collected and the historic memory of the construction; it is also an operational tool for planning conservation interventions and future maintenance.

All information is contained in a dynamic and interchangeable database, and every update is immediately quantifiable for monitoring the condition of the building, reducing the traditional manual operations.

Although many bottlenecks still exist in the implementation of efficient BIM systems for Cultural Heritage, HBIM simplifies the data management, leaving more time for other investigations, especially those that must necessarily be carried out in the field.

Waiting for the implementation of BIM authoring tools more oriented to Cultural Heritage needs, it would be necessary to establish common criteria for using current software in HBIM by the wide community operating in this field.

Acknowledgements The authors thank Prof. Maria Di Benedetto for the support provided on the decay characterization and conservation project, Filippo Fiaschi for his collaboration in the survey campaign, Giuseppe Granato and Gianni Abate for their help in GNSS acquisition and Arch. Luigi di Muccio (Soprintendenza Archeologia Belle Arti e Paesaggio per le Provincie di Caserta e Benevento).

Funding Information Open access funding provided by Università degli Studi di Firenze within the CRUI-CARE Agreement.

Open Access This article is licensed under a Creative Commons Attribution 4.0 International License, which permits use, sharing, adaptation, distribution and reproduction in any medium or format, as long as you give appropriate credit to the original author(s) and the source, provide a link to the Creative Commons licence, and indicate if changes were made. The images or other third party material in this article are included in the article's Creative Commons licence, unless indicated otherwise in a credit line to the material. If material is not included in the article's Creative Commons licence and your intended use is not permitted by statutory regulation or exceeds the permitted use, you will need to obtain 
permission directly from the copyright holder. To view a copy of this licence, visit http://creativecommons.org/licenses/by/4.0/.

\section{References}

Aparicio Resco P, Figueiredo C (2017) El grado de evidencia históricoarquelógica de la reconstrucciones virtuales: hacia una escala de representación gráfica. Revista Otarq 1:233-247. https://doi.org/ 10.23914/otarq.v0i1.96

Apollonio FI, Basilissi V, Callieri M, Dellepiane M, Gaiani M, Ponchio F, Rizzo F, Rubino AR, Scopigno R, Sobrà G (2017) A 3D-centered information system for the documentation of a complex restoration intervention. J Cult Herit 29:89-99. https://doi.org/10.1016/j.culher. 2017.07.010

Banfi F (2020) HBIM, 3D drawing and virtual reality for archaeological sites and ancient ruins. Virtual Archaeol Rev 11(23) In press. https:// doi.org/10.4995/var.2020.12416

Barazzetti L, Previtali M, Scaioni M (2020) Procedures for condition mapping using 360 images. Int J Geo-Inform 9(1):34. https://doi. org/10.3390/ijgi9010034

Bolognesi CM (2018) 3D representation: a survey for HBIM model, 3D modeling e BIM. In: Empler T, Valenti GM (eds) 3D modeling \& BIM Nuove Frontiere. DEI, Roma, pp 166-181

Boeykens S, Maekelberg S, De Jonge K (2018) (Re-)creating the past: 10 years of digital historical reconstructions using BIM. Int J Digit Art Hist 3:63-84. https://doi.org/10.11588/dah.2018.3.32544

Borin P, Cavazzini F (2019) Condition assessment of RC bridges, integrating machine learning, photogrammetry and BIM, International Archives of the Photogrammetry, Remote Sensing and Spatial Information Sciences, Volume XLII-2/W15, https://doi.org/10. 5194/isprs-archives-XLII-2-W15-201-2019

Brioso X, Calderón C, Aguilar R, Pando MA (2019) Preliminary methodology for the integration of lean construction, BIM and virtual reality in the planning phase of structural intervention in heritage structures. In: Structural analysis of historical constructions RILEM Bookseries, 18:484 492. Springer, Cham. https://doi.org/10.1007/ 978-3-319-99441-3 52

Canestrini F, Iacono MR (eds) (2007) L'acquedotto Carolino. L'Aperia, Caserta

Campanaro DM, Landeschi G, Dell'Unto N, Leander Touati AM (2016) 3D GIS for cultural heritage restoration: a 'white box' workflow. J Cult Herit 18:321-332. https://doi.org/10.1016/j.culher.2015.09. 006

D. Lgs. 560/2017 Ministero Infrastrutture e Trasporti Decreto 1 Dicembre 2017 n. 560. http://www.mit.gov.it/normativa/decreto-ministerialenumero-560-del-01122017

Gennaro M, Fuscaldo MD (1991) Il degrado del Tufo Giallo Napoletano. Prime osservazioni sui fenomeni di degrado dei materiali tufacei usati come pietra da costruzione. Arkos 13:4-9

León-Robles CA, Reinoso-Gordo JF, González-Quiñones JJ (2019) Heritage Building Information Modeling (H-BIM) applied to a stone bridge. ISPRS Int J Geo-Inf 2019(8):121. https://doi.org/10.3390/ ijgi8030121
McGuire B, Atadero R, Clevenger C, Ozbek M (2016) Bridge Information Modeling for inspection and evaluation. J Bridg Eng 21:04015076. https://doi.org/10.1061/(ASCE)BE.1943-5592. 0000850

Morgenthal G, Hallermann N, Kersten J, Taraben J, Debus P, Helmrich M, Rodehorst V (2019) Framework for automated UAS-based structural condition assessment of bridges. Autom Construct 97: 77-95. https://doi.org/10.1016/j.autcon.2018.10.006

Murphy M, McGovern E, Pavia S (2009) Historic building information modelling (HBIM). Structural Survey, Vol. 27 Iss 4 pp. 311-327 https://doi.org/10.1108/02630800910985108

Negri A, Russo J (2008) Degrado dei materiali lapidei: proposta di simbologia grafica In: Trattato di restauro architettonico, vol. X, Secondo aggiornamento (Carbonara G ed.), UTET, Torino, 533-544

Pybus C, Graham K, Doherty J, Arellano N, Fai S (2019) New realities for Canada's parliament: a workflow for preparing heritage BIM for game engines and virtual reality. Int Arch Photogram Remote Sens Spat Inf Sci XLII-2(W15):945-952. https://doi.org/10.5194/isprsarchives-XLII-2-W15-945-2019

Tsilimantou E, Delegou ET, Nikitakos IA, Ioannidis C, Moropoulou A (2020) GIS and BIM as integrated digital environments for modeling and monitoring of historic buildings. Appl Sci 10(3):1078. https://doi.org/10.3390/app10031078

Tucci G, Bonora V, Conti A, Fiorini L (2017) Digital workflow for the acquisition and elaboration of $3 \mathrm{~d}$ data in a monumental complex: the fortress of Saint John the Baptist in Florence. Int Arch Photogram Remote Sens Spat Inf Sci XLII-2(W5):679-686. https://doi.org/10. 5194/isprs-archives-XLII-2-W5-679-2017

Tucci G, Conti A, Fiorini L (2014) The mock-up of the "Ratto Delle Sabine" by Giambologna: making and utilization of a 3D model. ICONARP International Journal of Architecture and Planning, 2(2): 73-83. Retrieved from http://iconarp.selcuk.edu.tr/iconarp/article/ view/63

Tucci G, Conti A, Fiorini L, Corongiu M, Valdambrini N, Matta C (2019a) M-BIM: a new tool for the Galleria dell'Accademia di Firenze. Virt Archaeol Rev 10(21):40-55. https://doi.org/10.4995/ var.2019.11943

Tucci G, Corongiu M, Flamigni F, Comparini A, Panighini F, Parisi EI, Arcidiaco L (2019b) The validation process of a 3D multisource/ multiresolution model for railway infrastructures. Appl Geomat. https://doi.org/10.1007/s12518-019-00286-3

UNESCO (1997) 18th-Century Royal Palace at Caserta with the Park, the Aqueduct of Vanvitelli, and the San Leucio Complex. Retrieved online: https://whc.unesco.org/en/list/549/ Accessed 10/03/2020

UNI 11182:2006, Materiali lapidei naturali ed artificiali. Descrizione della forma di alterazione - Termini e definizioni, Milano, 2006

Wing E (2017) The Autodesk Revit World. In: Autodesk® Revit® 2017 for Architecture, E. Wing (Ed.). https://doi.org/10.1002/ 9781119415589.ch1

Xiao W, Mills J, Guidi G, Rodríguez-Gonzálvez P, Gonizzi Barsanti S, González-Aguilera D (2018) Geoinformatics for the conservation and promotion of cultural heritage in support of the UN Sustainable Development Goals. ISPRS J Photogramm Remote Sens 142:389-406. https://doi.org/10.1016/j.isprsjprs.2018.01.001 